\title{
Immunological effects of vaccines combined with granulocyte colony-stimulating factor on a murine WEHI-3 leukemia model
}

\author{
JINQIU CHEN ${ }^{1}$, MILING ZHANG ${ }^{2}$, FULING ZHOU ${ }^{1}$, JIN WANG ${ }^{1}$, BEN NIU $^{1}$ and WANGGANG ZHANG ${ }^{1}$ \\ ${ }^{1}$ Department of Clinical Hematology, Second Affiliated Hospital, Medical School of Xi'an Jiaotong University, Xi'an, \\ Shanxi 710004; ${ }^{2}$ Department of Hematology, The First People's Hospital of Xianyang, Xianyang, Shanxi 712000, P.R. China
}

Received January 26, 2016; Accepted December 16, 2016

DOI: $10.3892 / \mathrm{ol} .2017 .5731$

\begin{abstract}
Granulocyte colony-stimulating factor (G-CSF) mobilizes regulatory $\mathrm{T}$ cells (Tregs) from bone marrow into the peripheral blood, by reducing the expression of stromal cell-derived factor-1 $\alpha$ (SDF-1 $\alpha)$. However, G-CSF has rarely been studied in acute myeloid leukemia (AML) immunotherapy. The present study performed a Transwell migration assay in vitro to determine the contribution of SDF-1 $\alpha$ to the migration of leukemia cells, and the effects of G-CSF were evaluated. The effects of G-CSF on SDF-1 $\alpha$ and Tregs in the AML microenvironment were examined, by employing a WEHI-3-grafted BALB/c mouse AML model (AML-M4). It is evident that G-CSF reversed immunosuppression of the AML microenvironment by reducing SDF- $1 \alpha$ in bone marrow and elevating Tregs in the peripheral blood in in vivo studies. Furthermore, AML mice treated with vaccines combined with G-CSF achieved a longer survival time than those treated with vaccines without G-CSF, showing the efficiency of the regimen. The present study demonstrates the effects of G-CSF on the mobilization of leukemia cells and Tregs into the peripheral blood. In addition, immunotherapy with G-CSF priming represents a promising therapeutic strategy of targeting the immunosuppression.
\end{abstract}

\section{Introduction}

Acute myeloid leukemia (AML) is the predominant type of acute leukemia in adults (1). In AML patients who achieve complete remission following induction chemotherapy, a significant percentage of patients relapse within the first three years (2). Granulocyte colony-stimulating factor (G-SCF) priming, combined with chemotherapy, has been reported

Correspondence to: Professor Wanggang Zhang, Department of Clinical Hematology, Second Affiliated Hospital, Medical School of Xi'an Jiaotong University, 157 West Five Road, Xi'an, Shanxi 710004, P.R. China

E-mail: zhangwanggang2003@yahoo.com

Key words: vaccines, granulocyte colony-stimulating factor, acute myeloid leukemia, regulatory $\mathrm{T}$ cells, stromal cell-derived factor- $1 \alpha$ to be an effective and well-tolerated regimen in refractory or relapsed AML patients who are not eligible for intensive chemotherapy (3-6). In addition, immunotherapy is an active modality (7) and has had various levels of successes (8). However, there are few detailed studies about whether G-CSF makes a difference on immunotherapy in AML.

Cluster of differentiation (CD) $4^{+} / \mathrm{CD} 25^{+} /$forkhead box protein $\mathrm{P} 3\left(\mathrm{Foxp}^{+}\right.$) regulatory T cells (Tregs) are a subpopulation of $\mathrm{T}$ cells with a suppressive activity on immune responses (9). Tregs that exist in the AML microenvironment (10), and other cancer bearing individuals, (11-14) are mediators of immune suppression. It is known that inhibiting Treg function in cancer patients is an essential procedure to achieve successful immunotherapy in clinical practice $(15,16)$. As previously reported, chemokine stromal cell-derived factor-1 $\alpha(\mathrm{SDF}-1 \alpha)$, also termed chemokine CXC motif ligand 12, which is expressed in bone marrow, is involved in inducing Treg chemotaxis and adhesion, as well as inducing hematopoietic stem cells (HSCs) $(17,18)$. Activation of SDF-1 $\alpha$ signals increases recruitment of Tregs to the tumor microenvironment $(17,19)$, and it is a potential mechanism of tumor resistance to chemotherapy and immunotherapy (20). G-CSF, which was initially used to increase the production of neutrophils in patients with chemotherapy-induced neutropenia and transit HSCs from bone marrow to the peripheral blood for transplantation (21), mobilizes Tregs from bone marrow into the peripheral blood through reducing marrow-derived SDF-1 $\alpha$ expression (17).

Based on these studies, the present study examined the immunological effect of G-CSF on the tumor vaccines. An established syngeneic leukemia mouse model using the murine AML WEHI-3 cell line $(22,23)$ was used to determine whether the function of the vaccine was improved in vivo following administration of G-CSF.

\section{Materials and methods}

Cells and reagents. The human monocytic leukemia U937 cell line and murine AML WEHI-3 cell line were maintained in the laboratory of the Department of Clinical Hematology, Second Affiliated Hospital, Medical School of Xi'an Jiatong University (Xi'an, China) and were grown in RPMI-1640 medium supplemented with $10 \%$ fetal bovine serum (HyClone; GE Healthcare Life Sciences, Logan, UT, USA) and 1\% 
penicillin-streptomycin $(100 \mathrm{U} / \mathrm{ml}$ penicillin and $100 \mathrm{mg} / \mathrm{ml}$ streptomycin). Antibodies for flow cytometry (FCM; fluorescein isothiocyanate (FITC) anti-mouse CD4 [dilution, 1:100; cat. no. 11-0042], allophycocyanin (APC) anti-mouse CD25 [dilution, 1:100; cat. no. 17-0251], phycoerythrin (PE) anti-mouse/rat Foxp3 [dilution, 1:40; cat. no. 12-5773]) were purchased from eBioscience, Inc. (cat. co. 88-8111; San Diego, CA, USA). The mouse SDF-1 $\alpha$ ELISA kits were bought from R\&D Systems, Inc. (cat. no. MCX120; Minneapolis, MN, USA). The recombinant human granulocyte colony-stimulating factor (rhG-CSF) was provided by GeneScience Pharmaceuticals Co., Ltd. (Changchun, China).

Transwell migration assay. For migration studies, U937 and WEHI-3 cells $\left(5 \times 10^{6}\right.$ cells $\left./ \mathrm{ml}\right)$ suspended in RPMI-1640 medium were placed in the upper chambers of Transwell plates (pore size, $5 \mu \mathrm{m}$; Costar; Corning Incorporated,

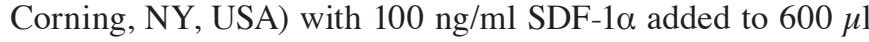
RPMI-1640 in the lower chambers. Following incubation for $4 \mathrm{~h}$ at $37^{\circ} \mathrm{C}$ in a humidified $\mathrm{CO}_{2}$ incubator, non-migrated $\mathrm{U} 937$ cells that remained on the upper chamber of the insert were removed by placing the insert into a sterile 24 -well plate, and cells migrating across the membrane were photographed with a digital camera (x100 magnification; Olympus Corporation, Tokyo, Japan). U937 cells that migrated to the lower chambers were collected in a $1.5 \mathrm{ml}$ centrifuge tube, centrifuged at $100 \mathrm{x} g$ for $5 \mathrm{~min}$ at room temperature, re-suspended in $100 \mu \mathrm{l}$ PBS and counted on a hemocytometer in an inverted microscope (x100 magnification; Nikon Corporation, Tokyo, Japan). The migrated U937 cells were spread on polylysine-coated slides (Wuhan Boster Biological Technology, Ltd., Wuhan, China), fixed in methyl alcohol for 5 min and stained with 4',6-diamidino-2-phenylindole. Stained cells were visualized in five randomly selected microscopic fields (x100 magnification) and photographed with a mercury fluorescence lamp (Nikon Corporation). WEHI-3 cells that had not migrated and remained in the upper chamber were removed by wiping with a cotton swab, and the cells that had migrated were fixed in methyl alcohol for $30 \mathrm{~min}$ and stained with $0.1 \%$ crystal violet. The number of WEHI-3 cells on the lower surface of the filter membrane was determined using a light microscope (x100 magnification; Olympus Corporation) and ImageJ software (version 1.47; National Institutes of Health, Bethesda, MD, USA). All experiments were conducted in triplicate.

Leukemia mouse model.All animal experiments were reviewed and approved by the Ethics Committee of the Medical College, Xi'an Jiaotong University (Xi'an, China). Male BALB/c wild-type mice (6 to 8 weeks old) were purchased from the Laboratory Animal Center, Medical College of Xi'an Jiaotong University and maintained under specific pathogen-free conditions, with a $12 / 12 \mathrm{~h} \mathrm{light/dark} \mathrm{cycle} \mathrm{at} 21 \pm 2^{\circ} \mathrm{C}$ and ad libitum access to food and water, and were handled according to standard protocols for the use of laboratory animals under specific pathogen-free conditions. In total, 40 mice were randomly divided into four groups ( $\mathrm{n}=10$ per group). For the syngeneic leukemia-implanted mouse acute myelomonocytic leukemia model (AML-M4), BALB/c mice were injected intravenously through their tail vein with WEHI- 3 cells $\left(1 \times 10^{6}\right.$ cells/animal $)$ in $500 \mu 1$ of PBS $(22,23)$.
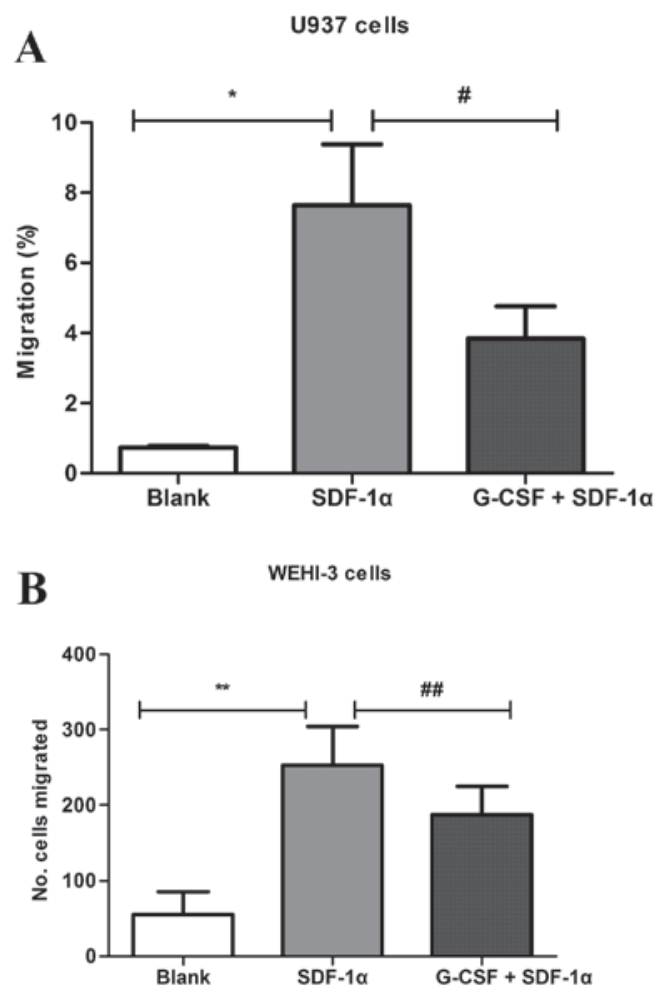

Figure 1. The effect of SDF-1 $\alpha$ on (A) U937 and (B) WEHI-3 cell migration with or without G-CSF. G-CSF decreases U937 and WEHI-3 cell migration in response to the SDF- $1 \alpha$ chemokine. ${ }^{*} \mathrm{P}<0.05$ vs. blank group; ${ }^{\prime \prime} \mathrm{P}<0.05$ vs. control group. ${ }^{* *} \mathrm{P}<0.05$ vs. blank group; ${ }^{\# \prime} \mathrm{P}<0.05$ vs. control group. G-CSF, granulocyte colony-stimulating factor; SDF-1 $\alpha$, stromal cell-derived factor- $1 \alpha$.

Tumor vaccines. WEHI-3 cells $\left(1 \times 10^{6}\right.$ cells $\left./ \mathrm{ml}\right)$ were inactivated in mitomycin-C and mixed with recombinant mouse interleukin-2 (rmIL-2) $(400 \mathrm{U} / \mathrm{ml})$, recombinant mouse granulocyte-macrophage colony-stimulating factor (rmGM-CSF) $(1 \mu \mathrm{g} / \mathrm{ml})$ and incomplete Freund's adjuvant (24). The vaccines were administered on days 15, 18, 22 and 25 following injection with WEHI-3 cells.

Mobilization of mice. G-CSF ( $1 \mu \mathrm{g} / 10 \mathrm{~g}$ weight) was administered to two groups of mice subcutaneously from day 26-30, following injection of WEHI-3 cells. At $6 \mathrm{~h}$ after the last injection, five mice in each group were randomly sacrificed by cervical dislocation, and peripheral blood, spleens, and femurs were collected as described in a previous study (25). The remaining five mice in each group were raised for observation of survival time until day 50 .

ELISA. SDF-1 $\alpha$ levels in the bone marrow supernatant were determined by using commercially available mouse CXCL12/SDF-1 alpha ELISA kits (cat. no. MCX120 R\&D Systems, Inc.) following the manufacturer's protocol. The bone marrow supernatant and peripheral serum samples were added to the anti-SDF-1 $\alpha$ pre-coated wells (with the exception of the control samples), followed by the addition of horseradish peroxidase-labeled detection antibody (cat. no. 892403; R\&D Systems, Inc.). The plates were incubated for $1 \mathrm{~h}$ at room temperature and subsequently washed five times with the wash buffer, then detected with $50 \mu 1$ substrates A and B. Reactions were stopped with stop solution, and absorbance at $450 \mathrm{~nm}$ was measured on 
A a

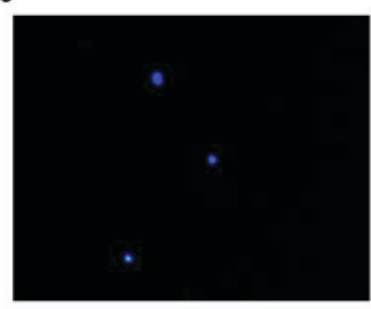

B

a

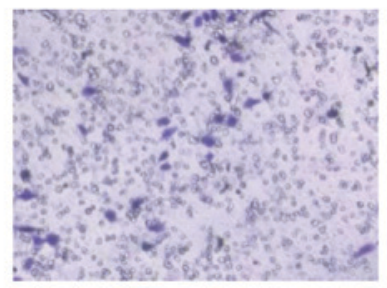

U937 cells

b

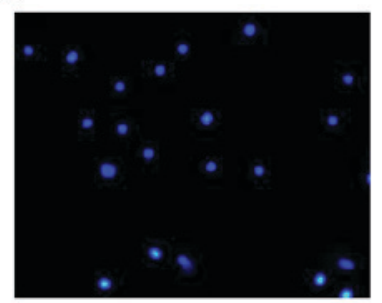

WEHI- 3 cells

b

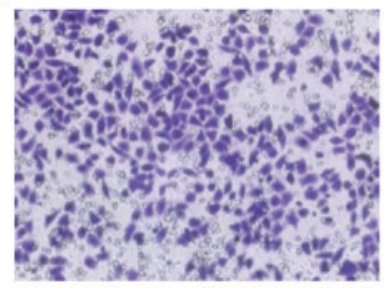

c

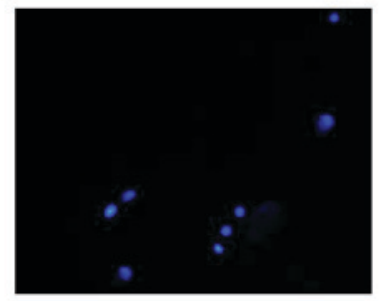

c

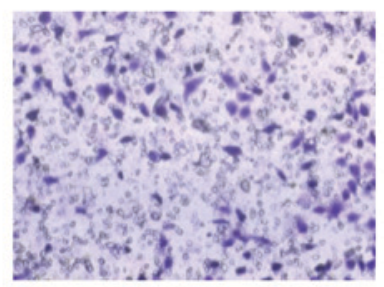

Figure 2. G-CSF inhibits cell migration with SDF-1 $\alpha$ exposure in U937 and WEHI-3 cells. Representative panels show migrated (A) U937 and (B) WEHI-3 cells in the lower chambers. The images in (A) were obtained by photographing the migrated U937 cells, which were stained with DAPI, on a fluorescence microscope. The images in (B) were obtained by photographing the Transwell membranes using a light microscope. (a) G-CSF and SDF-1 $\alpha$ no treatment (magnification, x100). (b) SDF-1 $\alpha 100 \mathrm{ng} / \mathrm{ml}$ (magnification, x100). (c) G-CSF pretreated for $18 \mathrm{~h}$ and SDF-1 $\alpha 100 \mathrm{ng} / \mathrm{ml}$ (magnification, x100). G-CSF, granulocyte colony-stimulating factor; SDF-1 $\alpha$, stromal cell-derived factor-1 $\alpha$; DAPI, 4',6-diamidino-2-phenylindole.

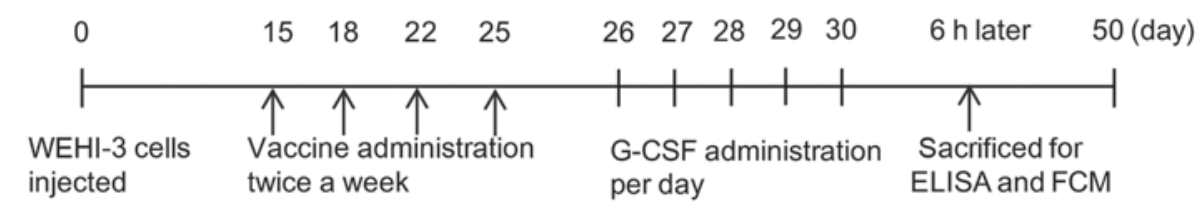

Figure 3. Schematic diagram of the in vivo study. Mice in groups 1, 2, 3 and 4 were all injected with WEHI-3 cells on day 0 . Groups 3 and 4 were then treated with vaccines. Groups 2 and 4 were primed with G-CSF. G-CSF, granulocyte colony-stimulating factor; FCM, flow cytometry.

a microplate reader (BioTek Instruments, Inc., Winooski, VA, USA).

FCM. Single cell suspensions of spleen cells and leukocytes in the peripheral blood were directly stained with FITC-conjugated anti-mouse CD4 (dilution, 1:100) and APC-conjugated anti-mouse CD25 (dilution, 1:100) for $30 \mathrm{~min}$ on ice. The cells were washed with cold flow cytometry staining buffer (eBioscience, Inc.) and then resuspended in $1 \mathrm{ml}$ of fixation/permeabilization working solution (eBioscience, Inc.) at $4^{\circ} \mathrm{C}$ in the dark overnight. The cells were washed twice with $1 \mathrm{X}$ permeabilization buffer (eBioscience, Inc.) and incubated for 30 min in $1 \mathrm{X}$ permeabilization buffer containing PE-conjugated anti-mouse Foxp3 (dilution, 1:40) antibody. Lymphocytes were gated by plotting forward vs. side scatter, followed by gating on CD4+ T cells, and these cells were then analyzed for the expression of CD25 and FoxP3.

\section{Results}

G-CSF decreases U937 and WEHI-3 cell migration induced by the SDF-1 $\alpha$ chemokine in vitro. As demonstrated in the Transwell migration assay, SDF- $1 \alpha$ increased migration of U937 and WEHI-3 cells to the lower chambers over $4 \mathrm{~h}$ culture (Figs. $1 \mathrm{~A}$ and $\mathrm{B} ; 2 \mathrm{Ab}$ and $\mathrm{Bb}$ ), consistent with previous studies (26). U937 and WEHI-3 cells were cultured with G-CSF for $18 \mathrm{~h}$ and SDF-1 $\alpha$ was added to the lower chambers. It is evident that the migration was significantly decreased $(\mathrm{P}<0.05)$ in the two cells following treatment with G-CSF, compared with the control group (Figs. $1 \mathrm{~A}$ and $\mathrm{B} ; 2 \mathrm{Ac}$ and $\mathrm{Bc}$ ).

$G$-CSF leads to in vivo reduction of SDF-1 $\alpha$ in bone marrow in AML and vaccination groups. A schematic diagram of the in vivo study was exhibited in Fig. 3. ELISA results demonstrated that the concentrations of SDF- $1 \alpha$ in the bone marrow supernatant had significantly decreased $(\mathrm{P}<0.05)$ following the administration of G-SCF in AML mice and vaccination groups (Fig. 4).

G-CSF increases Tregs in the peripheral blood and spleen of AML and vaccination groups. FCM was performed to investigate the percentage of $\mathrm{CD}^{+} / \mathrm{CD} 25^{+} / \mathrm{FoxP}^{+}$Tregs. Results revealed that the level of Tregs was elevated in the peripheral blood (Fig. 5) and spleen (Fig. 6), following administration of G-CSF in AML mice. In addition, the same phenomenon 


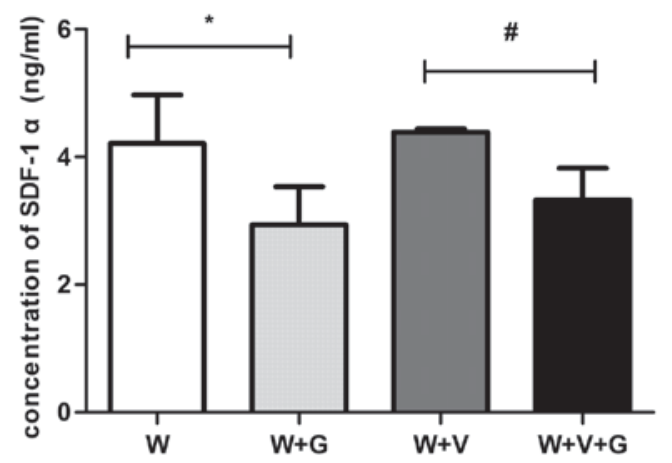

Figure 4. Effect of G-CSF on the concentration of SDF-1 $\alpha$ in mouse bone marrow. G-CSF reduced SDF- $1 \alpha$ in the bone marrow in acute myeloid leukemia and vaccination groups. ${ }^{*} \mathrm{P}<0.05,{ }^{\text {"P}} \mathrm{P}<0.05$. W, WEHI-3; $\mathrm{W}_{+} \mathrm{G}$, WEHI-3 + G-CSF; W + V, WEHI-3 + vaccines; W + V + G, WEHI-3 + vaccines + G-CSF; G-CSF, granulocyte colony-stimulating factor; SDF- $1 \alpha$, stromal cell-derived factor- $1 \alpha$.

A

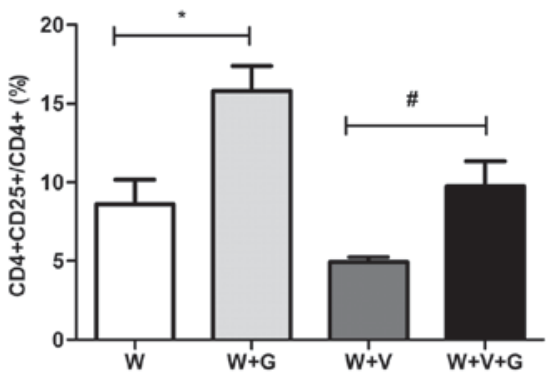

B

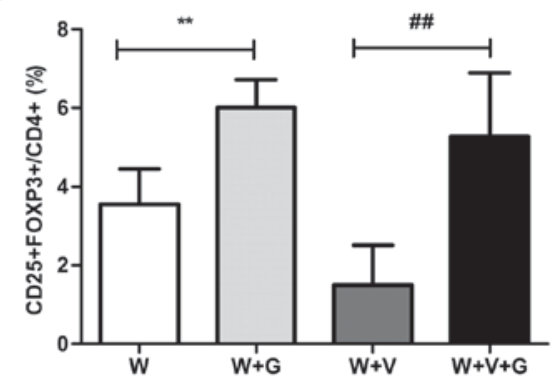

C

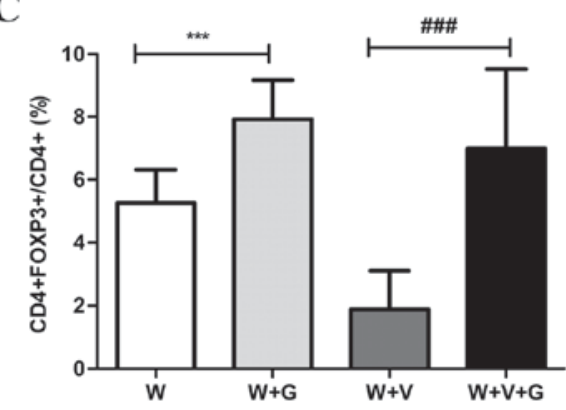

Figure 5. G-CSF increases the frequency of regulatory T cells in the peripheral blood of acute myeloid leukemia and vaccination groups. (A) The ratio of $\mathrm{CD}^{+} \mathrm{CD} 25^{+}$cells to $\mathrm{CD} 4^{+} \mathrm{T}$ cells in each group analyzed by $\mathrm{FCM}$. ${ }^{*} \mathrm{P}<0.05,{ }^{\#} \mathrm{P}<0.05$. (B) The ratio of $\mathrm{CD} 25^{+} \mathrm{FoxP} 3^{+}$cells to $\mathrm{CD} 4{ }^{+} \mathrm{T}$ cells in each group analyzed by FCM. ${ }^{* *} \mathrm{P}<0.05,{ }^{\# *} \mathrm{P}<0.05$. (C) The ratio of $\mathrm{CD} 4{ }^{+} \mathrm{Fox} \mathrm{P}^{+}$ cells to $\mathrm{CD}^{+} \mathrm{T}$ cells in each group analyzed by FCM. ${ }^{* * *} \mathrm{P}<0.05,{ }^{\# \#} \mathrm{P}<0.05$. W, WEHI-3; W + G, WEHI-3 + G-CSF; W + V, WEHI-3 + vaccines; W + V + G, WEHI-3 + vaccines + G-CSF; G-CSF, granulocyte colony-stimulating factor; FOXP3, forkhead box protein P3; CD, cluster of differentiation; FCM, flow cytometry.
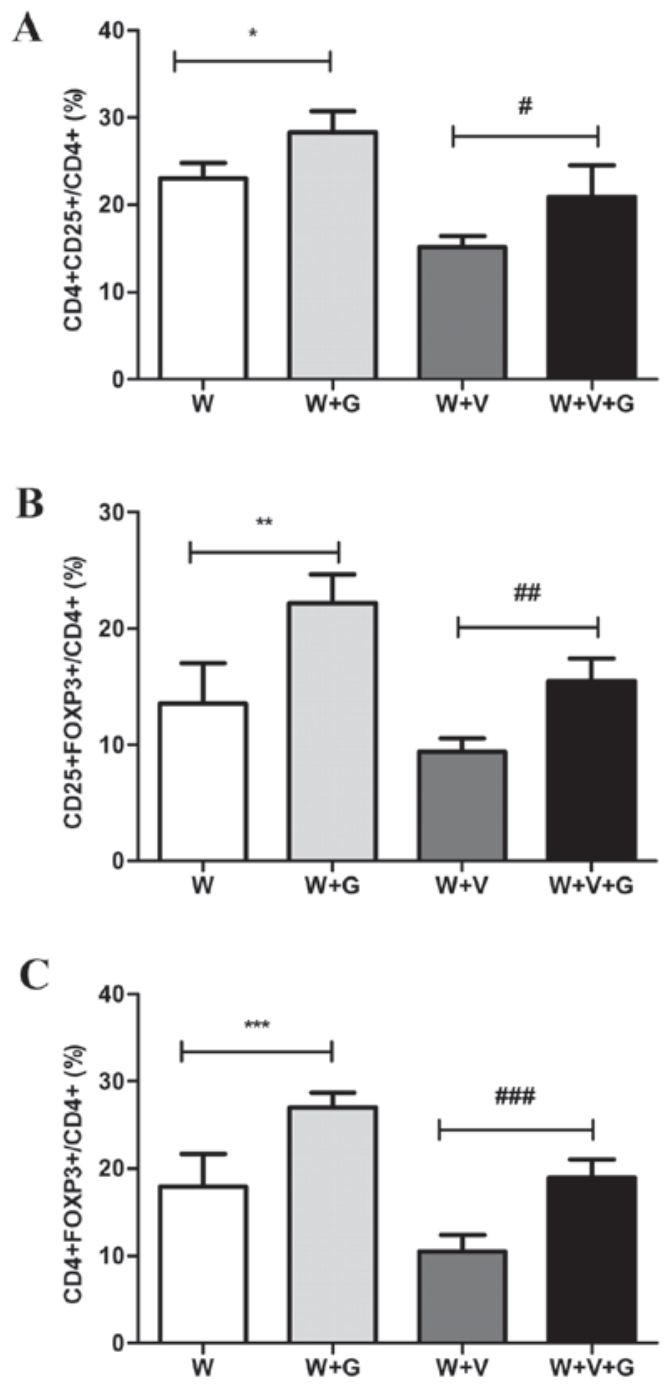

Figure 6. G-CSF increases the frequency of regulatory $\mathrm{T}$ cells in the spleen of acute myeloid leukemia and vaccination groups. (A) The ratio of $\mathrm{CD} 4^{+} \mathrm{CD} 25^{+}$ cells to $\mathrm{CD} 4^{+} \mathrm{T}$ cells in each group analyzed by $\mathrm{FCM}$. ${ }^{*} \mathrm{P}<0.05,{ }^{~} \mathrm{P}<0.05$. (B) The ratio of $\mathrm{CD} 25^{+} \mathrm{FoxP}^{+}$cells to $\mathrm{CD} 4^{+} \mathrm{T}$ cells in each group analyzed by FCM. ${ }^{* *} \mathrm{P}<0.05,{ }^{\# \#} \mathrm{P}<0.05$. (C) The ratio of $\mathrm{CD} 4{ }^{+} \mathrm{FoxP} 3^{+}$cells to $\mathrm{CD} 4{ }^{+}$ $\mathrm{T}$ cells in each group analyzed by $\mathrm{FCM} .{ }^{* * *} \mathrm{P}<0.05,{ }^{\# \#} \mathrm{P}<0.05$. W, WEHI-3; W + G, WEHI-3 + G-CSF; W + V, WEHI-3 + vaccines; W + V + G, WEHI-3 + vaccines + G-CSF; G-CSF, granulocyte colony-stimulating factor; FOXP3, forkhead box protein $\mathrm{P} 3$; $\mathrm{CD}$, cluster of differentiation; FCM, flow cytometry.

was observed in the vaccination combined with G-CSF group (Figs. 5 and 6).

Vaccination induces Treg reduction in the peripheral blood and spleen of AML mice. To determine whether the leukemia vaccines can affect the percentage of Tregs in vivo, one group of AML mice were injected with the vaccines subcutaneously for two weeks. Data revealed that the level of Tregs in the peripheral blood and spleen of the vaccination group was significantly lower $(\mathrm{P}<0.05)$ than the AML group without vaccination (Table I).

Administration of G-CSF prolongs the survival time of vaccinated mice. To analyze the protective efficacy of G-CSF, the survival time of vaccinated mice with or without administration of G-CSF was assessed (Fig. 7). The vaccine-treated mice 
Table I. Comparison of the level of regulatory T cells in the peripheral blood between acute myeloid leukemia mice and vaccinated mice.

\begin{tabular}{lccc}
\hline & \multicolumn{2}{c}{ Percentage of Tregs, $\%$} \\
\cline { 2 - 4 } Group & $\mathrm{CD}^{+} / \mathrm{CD} 25^{+} / \mathrm{CD}^{+}$ & $\mathrm{CD}^{+} 5^{+} / \mathrm{FoxP}^{+} / \mathrm{CD}^{+}$ & $\mathrm{CD}^{+} / \mathrm{FoxP}^{+} / \mathrm{CD}^{+}$ \\
\hline WEHI-3 & $8.60 \pm 1.57$ & $3.56 \pm 0.88$ & $5.22 \pm 1.05$ \\
Vaccination & $4.95 \pm 0.30^{\mathrm{a}}$ & $1.50 \pm 1.01^{\mathrm{b}}$ & $1.88 \pm 1.23^{\mathrm{c}}$ \\
WEHI-3 + G-CSF & $15.82 \pm 1.58$ & $6.02 \pm 0.70$ & $7.92 \pm 1.24$ \\
WEHI-3 + V + G-CSF & $9.74 \pm 1.60$ & $5.28 \pm 1.61$ & $6.99 \pm 2.53^{\mathrm{d}}$ \\
\hline
\end{tabular}

Data are presented as the mean \pm standard deviation. ${ }^{\mathrm{a}} \mathrm{P}<0.05,{ }^{\mathrm{b}} \mathrm{P}<0.05,{ }^{\mathrm{c}} \mathrm{P}<0.05$, compared with the WEHI- 3 group; ${ }^{\mathrm{d}} \mathrm{P}<0.05$, compared with the WEHI-3 + G-CSF group. G-CSF had a significantly prolonged survival time among the four groups. G-CSF, granulocyte colony-stimulating factor; W, WEHI-3; W + G, WEHI-3 + G-CSF; W + V, WEHI-3 + vaccines; W + V + G, WEHI-3 + vaccines + G-CSF; G-CSF, granulocyte colony-stimulating factor; FOXP3, forkhead box protein P3; CD, cluster of differentiation.

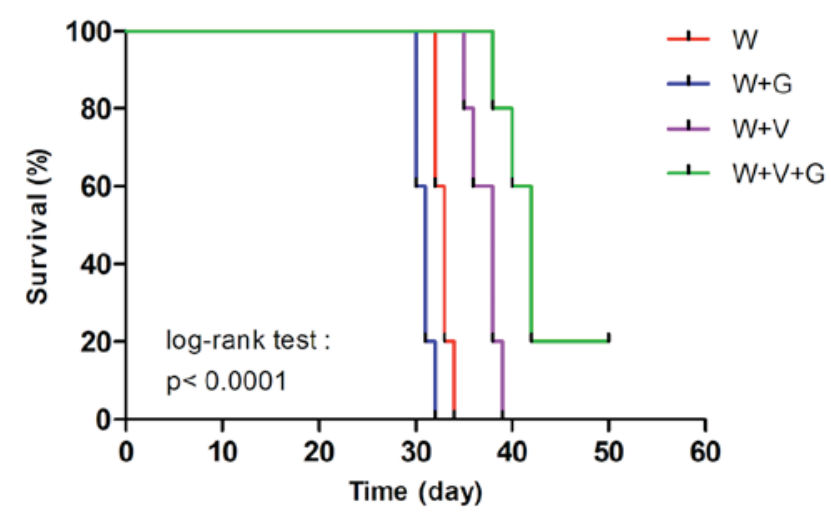

Figure 7. Kaplan-Meier curve representing the survival time of mice in different groups. Log-rank test showed a significant difference in the overall survival among the groups $(\mathrm{P}<0.001 ; \mathrm{n}=5$ for each group). The vaccine-treated mice mobilized with G-CSF had a significantly prolonged survival time among the four groups. G-CSF, granulocyte colony-stimulating factor; W, WEHI-3; W + G, WEHI-3 + G-CSF; W + V, WEHI-3 + vaccines; $\mathrm{W}+\mathrm{V}+\mathrm{G}, \mathrm{WEHI}-3$ + vaccines + G-CSF.

mobilized with G-CSF had a significantly $(\mathrm{P}<0.01)$ prolonged survival time (42 days) compared with the control mice that received vaccines without G-CSF (38 days) and AML mice (33 days).

\section{Discussion}

Cancer cell-based vaccines combined with adjuvants are generally designed to induce an antigen to activate dendritic cells (DCs) (27-30). DC-based immunotherapies utilize monocyte-derived conventional DCs to prime cytotoxic $\mathrm{T}$ lymphocyte (CTL)-mediated immune responses (27-29,31). The administration of therapeutic vaccines can stimulate the host's own immune system to attack cancer cells $(32,33)$. Leukemia immunotherapy has been studied for a number of years (24) and the present study demonstrates that the aforementioned vaccines can also promote cellular immunity and enhance the cytotoxicity of CTL. G-CSF is a strong mobilizing factor for mononuclear cells and DCs (34), and it may enhance DC differentiation and activation, and antitumor responses (35-38).
Furthermore, G-CSF correlates with tumor vaccines efficacy (31). However, to the best of our knowledge, no studies have assessed the impact of G-CSF on AML vaccines. Considering the advantage of cancer vaccines and the role of G-CSF in immunity, the present study examined the efficiency of leukemia vaccines combined with G-CSF in AML mice.

The bone marrow microenvironment (BMM) provides a protective niche that supports growth and survival of HSCs (39) and the primary site of minimal residual disease following chemotherapy (40-42). The SDF-1 $\alpha$ is pivotal for regulation of homing to and retention of hematopoietic cells in the bone marrow. It was reported that over 20 types of cancer respond to SDF-1 $\alpha$ (43). In vitro studies demonstrated that adding SDF-1 $\alpha$ increased the migration of leukemia cells compared with the control group, which is consistent with previous studies (26). By contrast, co-culture of AML cells with G-CSF decreased migration of tumor cells to SDF-1 $\alpha$, suggesting that G-CSF may destroy the interaction between SDF-1 $\alpha$ and leukemia cells in BMM, thus driving more leukemia cells into the peripheral blood. In the present in vivo study, the peripheral blood smears of the AML mice demonstrated that with the administration of G-CSF, more leukemia cells migrated to the peripheral blood, which was in accordance with the findings of the in vitro study.

SDF-1 $\alpha$ also induces Treg chemotaxis and adhesion to BMM (17). Tregs are recruited to evade immunosurveillance in the microenvironment of AML (10), suppress effector cells and antigen presenting cells (APCs) and induce immunosuppression against cancer cells through cytokines (44-47). Previous studies have demonstrated that the in vivo administration of G-CSF could decrease the number of Tregs in the bone marrow and increase the number of Tregs in the peripheral blood $(17,48)$. Following application of G-CSF in AML mice, an increase in the number of Tregs in the peripheral blood was also detected. The lower level of Tregs in the bone marrow may reduce the immunosuppression in the microenvironment, thus improving the function of the vaccine. One approach to overcome evasion of immunosurveillance and promote antitumor response is the depletion of Tregs in the peripheral blood. Previous studies have demonstrated that a number of therapies can reduce Tregs in vivo. For example, imatinib reduces Tregs frequency and immunosuppressive function in chronic myelogenous leukemia (CML) mice (49), 
the chaperone-rich cell lysate vaccine can resist Treg suppression (50), and lenalidomide reduces Tregs in tumor-bearing lymphoma mice (51). In the present study, AML mice were vaccinated, and it was detected that the tumor vaccines induced Treg reduction in the peripheral blood of AML mice. This suggests that the vaccines serve a direct role in overcoming tumor-induced immunosuppression. However, the vaccines combined with G-CSF did not decrease the percentage of Tregs in the peripheral blood compared with the control group, suggesting that other methods may be employed to target Tregs in the subsequent studies. Whether G-CSF priming combined with low-dose chemotherapy functions through SDF-1 $\alpha / \mathrm{CXCR} 4$ still requires further study. It can be speculated that G-CSF decreases the concentration of SDF- $1 \alpha$ in bone marrow and motivates the migration of leukemia cells and Tregs into the peripheral blood, where tumor cells are killed by the chemotherapy drugs.

Previous studies have reported that immunotherapy is effective for the treatment of AML (7,30). In the present study, it was observed that the survival time of the vaccination group was notably longer than the AML mice, demonstrating the direct antitumoral effect of the vaccines. Among all the groups, the one that was treated with tumor vaccines combined with G-CSF achieved the longest survival time, proving the efficiency of the regimen.

In conclusion, the present study suggests that combining tumor vaccines with G-CSF is a new, effective regimen for the treatment of AML. The results demonstrate that treating AML mice with G-CSF reverses immunosuppression in the tumor microenvironment. In addition, the tumor vaccines can delete Tregs in the peripheral blood, thus alleviating immune suppression further. Combining tumor vaccines with G-CSF regimen is shown to be a promising therapeutic strategy.

\section{Acknowledgements}

The present study was supported by Fundamental Research Funds for the Central Universities in China (grant no. 0602-08143041) and the National Natural Science Foundation of China (grant nos. 81270597; 81070441).

\section{References}

1. Martner A, Thorén FB, Aurelius J and Hellstrand K: Immunotherapeutic strategies for relapse control in acute myeloid leukemia. Blood Rev 27: 209-216, 2013.

2. Thol F, Schlenk RF, Heuser M and Ganser A: How I treat refractory and early relapsed acute myeloid leukemia. Blood 126: 319-327, 2015.

3. Zhang WG, Wang FX, Chen YX, Cao XM, He AL, Liu J, Ma XR, Zhao WH, Liu SH and Wang JL: Combination chemotherapy with low-dose cytarabine, homoharringtonine, and granulocyte colony-stimulating factor priming in patients with relapsed or refractory acute myeloid leukemia. Am J Hematol 83: 185-188, 2008.

4. Gu LF, Zhang WG, Wang FX, Cao XM, Chen YX, He AL, Liu J and Ma XR: Low dose of homoharringtonine and cytarabine combined with granulocyte colony-stimulating factor priming on the outcome of relapsed or refractory acute myeloid leukemia. J Cancer Res Clin Oncol 137: 997-1003, 2011.

5. Becker PS, Medeiros BC, Stein AS, Othus M, Appelbaum FR, Forman SJ, Scott BL, Hendrie PC, Gardner KM, Pagel JM, et al: G-CSF priming, clofarabine, and high dose cytarabine (GCLAC) for upfront treatment of acute myeloid leukemia, advanced myelodysplastic syndrome or advanced myeloproliferative neoplasm. Am J Hematol 90: 295-300, 2015.
6. Liu L, Zhang Y, Jin Z, Zhang X, Zhao G, Si Y, Lin G, Ma A, Sun Y, Wang L and Wu D: Increasing the dose of aclarubicin in low-dose cytarabine and aclarubicin in combination with granulocyte colony-stimulating factor (CAG regimen) can safely and effectively treat relapsed or refractory acute myeloid leukemia. Int J Hematol 99: 603-608, 2014.

7. Grosso DA, Hess RC and Weiss MA: Immunotherapy in acute myeloid leukemia. Cancer 121: 2689-2704, 2015.

8. La-Beck NM, Jean GW, Huynh C, Alzghari SK and Lowe DB: Immune checkpoint inhibitors: New insights and current place in cancer therapy. Pharmacotherapy 35: 963-976, 2015.

9. Halvorsen EC, Mahmoud SM and Bennewith KL: Emerging roles of regulatory $\mathrm{T}$ cells in tumour progression and metastasis. Cancer Metastasis Rev 33: 1025-1041, 2014.

10. Ustun C, Miller JS, Munn DH, Weisdorf DJ and Blazar BR: Regulatory $\mathrm{T}$ cells in acute myelogenous leukemia: Is it time for immunomodulation? Blood 118: 5084-5095, 2011.

11. Olkhanud PB, Baatar D, Bodogai M, Hakim F, Gress R, Anderson RL, Deng J, Xu M, Briest S and Biragyn A: Breast cancer lung metastasis requires expression of chemokine receptor CCR4 and T regulatory cells. Cancer Res 69: 5996-6004, 2009.

12. Ducloux D: Regulatory T cells and cancer: An undesired tolerance. Kidney Int 86: 16-18, 2014.

13. Joshi NS, Akama-Garren EH, Lu Y, Lee DY, Chang GP, Li A, DuPage M, Tammela T, Kerper NR, Farago AF, et al: Regulatory $\mathrm{T}$ cells in tumor-associated tertiary lymphoid structures suppress anti-tumor T cell responses. Immunity 43: 579-590, 2015.

14. Pastille E, Bardini K, Fleissner D, Adamczyk A, Frede A Wadwa M, von Smolinski D, Kasper S, Sparwasser T, Gruber AD, et al: Transient ablation of regulatory $\mathrm{T}$ cells improves antitumor immunity in colitis-associated colon cancer. Cancer Res 74: 4258-4269, 2014.

15. Colombo MP and Piconese S: Regulatory-T-cell inhibition versus depletion: The right choice in cancer immunotherapy. Nat Rev Cancer 7: 880-887, 2007.

16. Motz GT and Coukos G: Deciphering and reversing tumor immune suppression. Immunity 39: 61-73, 2013.

17. Zou L, Barnett B, Safah H, Larussa VF, Evdemon-Hogan M, Mottram P, Wei S, David O, Curiel TJ and Zou W: Bone marrow is a reservoir for $\mathrm{CD} 4{ }^{+} \mathrm{CD} 25^{+}$regulatory $\mathrm{T}$ cells that traffic through CXCL12/CXCR4 signals. Cancer Res 64: 8451-8455, 2004.

18. Tabe $\mathrm{Y}$ and Konopleva $\mathrm{M}$ : Advances in understanding the leukaemia microenvironment. Br J Haematol 164: 767-778, 2014

19. Shen X, Li N, Li H, Zhang T, Wang F and Li Q: Increased prevalence of regulatory $\mathrm{T}$ cells in the tumor microenvironment and its correlation with TNM stage of hepatocellular carcinoma. J Cancer Res Clin Oncol 136: 1745-1754, 2010.

20. Duda DG, Kozin SV, Kirkpatrick ND, Xu L, Fukumura D and Jain RK: CXCL12 (SDF1alpha)-CXCR4/CXCR7 pathway inhibition: An emerging sensitizer for anticancer therapies? Clin Cancer Res 17: 2074-2080, 2011.

21. Bendall LJ and Bradstock KF: G-CSF: From granulopoietic stimulant to bone marrow stem cell mobilizing agent. Cytokine Growth Factor Rev 25: 355-367, 2014.

22. Lin JP, Yang JS, Lu CC, Chiang JH, Wu CL, Lin JJ, Lin HL, Yang MD, Liu KC, Chiu TH and Chung JG: Rutin inhibits the proliferation of murine leukemia WEHI-3 cells in vivo and promotes immune response in vivo. Leuk Res 33: 823-828, 2009.

23. Wen YF, Yang JS, Kuo SC, Hwang CS, Chung JG, Wu HC, Huang WW, Jhan JH, Lin CM and Chen HJ: Investigation of anti-leukemia molecular mechanism of ITR-284, a carboxamide analog, in leukemia cells and its effects in WEHI-3 leukemia mice. Biochem Pharmacol 79: 389-398, 2010.

24. Zhang WG, Liu SH, Cao XM, Cheng YX, Ma XR, Yang Y and Wang YL: A phase-I clinical trial of active immunotherapy for acute leukemia using inactivated autologous leukemia cells mixed with IL-2, GM-CSF and IL-6. Leuk Res 29: 3-9, 2005.

25. Radford KJ, Tullett KM and Lahoud MH: Dendritic cells and cancer immunotherapy. Curr Opin Immunol 27: 26-32, 2014.

26. Kirkwood JM, Butterfield LH, Tarhini AA, Zarour H, Kalinski P and Ferrone S: Immunotherapy of cancer in 2012. CA Cancer J Clin 62: 309-335, 2012.

27. Ali OA, Emerich D, Dranoff G and Mooney DJ: In situ regulation of DC subsets and T cells mediates tumor regression in mice. Sci Transl Med 1: 8ra19, 2009.

28. Hansen M, Hjortø GM, Donia M, Met Ö, Larsen NB, Andersen MH, thor Straten P and Svane IM: Comparison of clinical grade type 1 polarized and standard matured dendritic cells for cancer immunotherapy. Vaccine 31: 639-646, 2013. 
29. Steinman RM and Banchereau J: Taking dendritic cells into medicine. Nature 449: 419-426, 2007.

30. Lichtenegger FS, Krupka C, Köhnke T and Subklewe M: Immunotherapy for acute myeloid leukemia. Semin Hematol 52: 207-214, 2015.

31. Ali OA, Verbeke C, Johnson C, Sands RW, Lewin SA, White D, Doherty E, Dranoff $\mathrm{G}$ and Mooney DJ: Identification of immune factors regulating antitumor immunity using polymeric vaccines with multiple adjuvants. Cancer Res 74: 1670-1681, 2014.

32. Lichtenegger FS, Schnorfeil FM, Hiddemann W and Subklewe M: Current strategies in immunotherapy for acute myeloid leukemia. Immunotherapy 5: 63-78, 2013.

33. Emens LA: Cancer vaccines: On the threshold of success. Exp Opin Emerging Drugs 13: 295-308, 2008.

34. Arpinati M, Green CL, Heimfeld S, Heuser JE and Anasetti C: Granulocyte-colony stimulating factor mobilizes $\mathrm{T}$ helper 2-inducing dendritic cells. Blood 95: 2484-2490, 2000.

35. Pulendran B, Banchereau J, Burkeholder S, Kraus E, Guinet E, Chalouni C, Caron D, Maliszewski C, Davoust J, Fay J and Palucka K: Flt3-ligand and granulocyte colony-stimulating factor mobilize distinct human dendritic cell subsets in vivo. J Immunol 165: 566-572, 2000.

36. Anderlini P: Effects and safety of granulocyte colony-stimulating factor in healthy volunteers. Curr Opin Hematol 16 35-40, 2009.

37. Greter M, Helft J, Chow A, Hashimoto D, Mortha A, Agudo-Cantero J, Bogunovic M, Gautier EL, Miller J, Leboeuf M, et al: GM-CSF controls nonlymphoid tissue dendritic cell homeostasis but is dispensable for the differentiation of inflammatory dendritic cells. Immunity 36: 1031-1046, 2012.

38. Vuckovic S, Kim M, Khalil D, Turtle CJ, Crosbie GV, Williams N, Brown L, Williams K, Kelly C, Stravos P, et al: Granulocyte-colony stimulating factor increases CD123hi blood dendritic cells with altered CD62L and CCR7 expression. Blood 101: 2314-2317, 2003.

39. Nwajei $\mathrm{F}$ and Konopleva M: The bone marrow microenvironment as niche retreats for hematopoietic and leukemic stem cells. Adv Hematol 2013: 953982, 2013.
40. Meads MB, Hazlehurst LA and Dalton WS: The bone marrow microenvironment as a tumor sanctuary and contributor to drug resistance. Clin Cancer Res 14: 2519-2526, 2008.

41. Konopleva $\mathrm{M}$ and Andreeff $\mathrm{M}$ : Targeting the leukemia microenvironment. Curr Drug Targets 8: 685-701, 2007.

42. Burger JA and Bürkle A: The CXCR4 chemokine receptor in acute and chronic leukaemia: A marrow homing receptor and potential therapeutic target. Br J Haematol 137: 288-296, 2007.

43. Balkwill F: The significance of cancer cell expression of the chemokine receptor CXCR4. Semin Cancer Biol 14: 171-179, 2004.

44. Maloy KJ and Powrie F: Regulatory T cells in the control of immune pathology. Nat Immunol 2: 816-822, 2001.

45. O'Garra A and Vieira P: Regulatory T cells and mechanisms of immune system control. Nat Med 10: 801-805, 2004

46. Shalev I, Schmelzle M, Robson SC and Levy G: Making sense of regulatory $\mathrm{T}$ cell suppressive function. Semin Immunol 23: 282-292, 2011.

47. Coleman CA, Muller-Trutwin MC, Apetrei C and Pandrea I: T regulatory cells: Aid or hindrance in the clearance of disease? J Cell Mol Med 11: 1291-1325, 2007.

48. Jun HX, Jun CY and Yu ZX: In vivo induction of T-cell hyporesponsiveness and alteration of immunological cells of bone marrow grafts using granulocyte colony-stimulating factor. Haematologica 89: 1517-1524, 2004

49. Larmonier N, Janikashvili N, LaCasse CJ, Larmonier CB, Cantrell J, Situ E, Lundeen T, Bonnotte B and Katsanis E: Imatinib mesylate inhibits $\mathrm{CD} 4{ }^{+} \mathrm{CD} 25^{+}$regulatory $\mathrm{T}$ cell activity and enhances active immunotherapy against BCR-ABL- tumors. J Immunol 181: 6955-6963, 2008.

50. Larmonier N, Fraszczak J, Lakomy D, Bonnotte B and Katsanis E: Killer dendritic cells and their potential for cancer immunotherapy. Cancer Immunol Immunother 59: 1-11, 2009.

51. Sakamaki I, Kwak LW, Cha SC, Yi Q, Lerman B, Chen J, Surapaneni S, Bateman S and Qin H: Lenalidomide enhances the protective effect of a therapeutic vaccine and reverses immune suppression in mice bearing established lymphomas. Leukemia 28: 329-337, 2014. 